\title{
A Normative Approach to Valuation, Value Enhancement and Financial Statement Reporting of Intellectual Capital
}

\author{
Michael So ${ }^{\mathrm{a}}$, Janek Ratnatunga ${ }^{\mathrm{b}}$ \\ ${ }^{a}$ United International College, Beijing Normal University and Hong \\ Kong Baptist University, China \\ ${ }^{\mathrm{b}}$ Institute of Certified Management Accountants, Australia
}

\begin{abstract}
Intellectual capital (IC) is increasingly seen as an integral part of a firm's value-creating processes and an essential strategic asset in creating corporate sustainable competitive advantage (Bukh, 2003; Chen, Cheng \& Hwang, 2005). Nevertheless, reporting on IC is currently inconsistent, incomparable, and incomplete because of a lack of consistent guidance. This paper presents a normative IC valuation and reporting framework based on the Capability Economic Value of Intangible and Tangible Assets $\left(\right.$ CEVITA $\left.^{\mathrm{TM}}\right)$ approach (Ratnatunga, Gray \& Balachandran, 2004). The proposed framework enables the application of CEVITA $^{\mathrm{TM}}$ to the valuation of intellectual capital capability and provides a theoretical foundation for future empirical studies in relation to IC valuation and reporting.
\end{abstract}

Keywords: Capability Economic Value of Intangible and Tangible Assets; Intellectual Capital; Valuation

\section{Introduction}

Today, intellectual capital (IC) is a major source of real value of firms and competitive advantage in marketplace (Cuganesan \& Petty, 2010; So, 2018). IC has been recognised as an essential strategic asset in creating corporate sustainable competitive advantage (Chen, Cheng \& Hwang, 2005) and it is seen as an integral part of a firm's value-creating processes (Bukh, 2003). To examine the relationship, Menor et al. (2007) measured the IC of 267 United States (US) manufacturing companies. They concluded that the IC played an important part for operational and 
business performance in those companies. Another study conducted by Tan et al. (2007) in 150 Singaporean companies indicated that future company performance was positively related to their IC. This view was also shared by Youndt et al. (2004) who claimed that IC-intensive companies were more competitive and therefore more successful.

It seems that IC is gradually replacing the traditional physical assets as the key determinant of corporate future performance. Knowledge assets have become structurally more important in value creation due to a shift from a production-oriented to knowledge-based economy (Seetharaman, Sooria \& Saravanan, 2002). This, in turn, means that physical and financial assets have become less dominant explanations of business success (Campbell \& Abdul Rahman, 2010).

Nevertheless, reporting on IC is currently inconsistent, incomparable, and incomplete because of a lack of consistent guidance. The issue of IC reporting requires us to consider what form IC reporting should take and which frameworks are most beneficial to users and producers. This highlights the need for a clear, universally applicable form of IC reporting combined with business models as proposed by the International Integrated Reporting Council in 2013. Whilst So (2014) investigated that managers generally perceive IC disclosure as being valuable in satisfying interests of various stakeholders of a firm; there is still no broad consensus on approach, reporting framework or even the underlying valuation philosophy pertaining to IC.

In order to regulate the reporting and the use of the intangible resources, a suitable framework of IC reporting needs to be established. Accordingly, researchers and policy makers are challenged to develop an IC measurement model that involves relating both tangible and intangible information in a single document but is likely to represent the diverse elements of an organization (Eccles \& Serafeim, 2011). In view of this requirement in measuring and reporting of intellectual capital, Ratnatunga (2002) advised that managers should view intangibles as the "capabilities" of an organisation. He explained that intangibles could be perceived as a form of competitive advantage rather than as fixed assets. Additionally, it should explain how IC capability could be enhanced via the targeted expenditure on certain aspects of IC. For example, an increase in training expenses could be treated as an enhancement in the capability of human assets (Ratnatunga, Gray \& Balachandran, 2004).

The model built on the Capability Economic Value of Intangible and Tangible Assets $\left(\right.$ CEVITA $\left.^{\mathrm{TM}}\right)$ approach was proposed by Ratnatunga et 
al. (2004) to consider the capability of intellectual capital. The normative model is this paper mainly consists of equations showing the change in IC capability value and an intellectual capital capability (ICC) balance sheet. The equations in the model provide a picture of the value-creation process within a firm and explanations of the contribution by support costs of the intangibles. This provides an ex-ante appraisal model to enable managers to pro-actively executive value-enhancing strategies. Moreover, the ICC balance sheet visualises both tangible and intangible resources and is more relevant to the firm's stakeholders. The IC capability value and the ICC balance sheet suggested a framework of valuing and reporting IC that could be employed to satisfy the needs of various company stakeholders.

The aim of this paper is to examine to what extent the $\left(\mathrm{CEVITA}^{\mathrm{TM}}\right)$ approach (Ratnatunga et al., 2004) can be adapted and applied to the valuation of ICC at a point in time, and this approach can be used in ICC enhancing processes. Accordingly, as part of the challenge to develop new approaches to business reporting, this paper contributes to provide a starting point for that endeavour by a normative approach of IC reporting and valuation.

The paper is structured as follows: The next section discusses various definitions given by researchers to the concept of intellectual capital. It then provides an explanation and hypothetical case example which would allow decision makers to expand their knowledge regarding IC aspects considered relevant to value of their firms. The paper then proposes an ICC balance sheet to incorporate more asset categories than those captured by traditional financial accounting statements.

\section{Definitions of Intellectual Capital}

It is difficult to provide a unified definition and accepted typology for IC (Martin-de-Castro et al., 2011) and while different definitions seem to adopt different approaches, it seems that their common element is that IC consists of intangible assets (MERITUM, 2002).

One important characteristic of intellectual capital is thus its intangible nature. Intellectual capital is a hidden asset that does not exist in physical form but holds value and can generate competitive advantage to the organisation (Choong, 2008). It represents the set of intangibles that are susceptible of being recognised as assets in accordance with the perspective of financial accounting (MERITUM, 2002). Martin-de- 
Castro et al. (2011), however, treat IC as a synonym for intangible or knowledge assets. They call IC as a capital because it could be regarded as a process of value creation.

From a strategic point of view, IC is regarded as the strategic assets of a firm with key characteristics of rarity, inimitability and nonsubstitutability (Riahi-Belkaoui, 2003). It is a crucial success factor for a firm's long-term profit and performance in a knowledge-based economy (Hsu \& Fang, 2009; Kong, 2010). Using a different approach, Mouritsen (2006) defines IC in a performative manner whereby the concept of IC is situation dependent. The meaning of IC could only be known in relation to specific instances of interaction. In this regard, IC is a representation of knowledge resources whose transformative qualities emerge in application (Mouritsen, 2006).

Later intellectual capital definitions have developed into three categories: Human capital, structural capital and relational capital (Abeysekera \& Guthrie 2004, 2005; Bozzolan, Favotto \& Ricceri, 2003; Brennan, 2001; Martin-de-Castro et al., 2011; Sveiby, 1997). A consensus seems to have emerged whereby IC can be divided into three major components: one relating to people skills and expertise, another to internal organisational structure, and a third to external structure. In an attempt to focus on competitive advantage, Ratnatunga (2002) views IC as a source of organisation's capabilities, rather than as an asset in a static approach.

\section{Intellectual Capital Reporting and Stakeholder Theory}

Stakeholders are defined as entities or individuals that can reasonably be expected to be significantly affected by the organisation's activities, products, and/or services, and whose actions can reasonably be expected to affect the ability of the organisation to successfully implement its strategies and achieve its objective. Examples of primary stakeholders include shareholders, creditors, employees, customers, suppliers and regulators.

For some decisions, such as the scope of the business report, the reasonable expectations and interests of stakeholders should be acknowledged in decisions about the content of the report. There has been some discussion on moving from a shareholder primacy perspective to a stakeholder primacy perspective on corporate reporting (Van Marrewijk, 2003). For example, Van Marrewijk (2003) proposed an 
extended framework of corporate social responsibility related to both the social, economic and environmental responsibility.

The traditional view is that the fiduciary duty of management is to protect shareholders' interests. On the other hand, the basic proposition of the stakeholder theory is that the firm's success is dependent on the successful management of all the relationships that a firm has with its stakeholders (Freeman, 1984). According to stakeholder theory, a manager of an organisation is expected to take and report on those activities that are expected by its stakeholders for the organisation to be involved in (Guthrie et al., 2004). Value is created based on the integration of the relationships and interests of groups of stakeholders in a way that guarantees the ongoing success of the organisation (McVea \& Freeman, 2005). Conflicts among stakeholders must be resolved so that regulation or political process can be avoided (Freeman, Wicks \& Parmar, 2004).

Stakeholder theory reflects a concept of accountability that is broader than just stewardship of shareholder interests. The theory suggests that all stakeholders have a right to be provided with information about how organisational activities impact upon them (Deegan \& Gordon, 1996). As per the ethical branch of stakeholder theory, companies regard disclosure as responsibility-driven because every stakeholder has a right to IC information (Beattie \& Thomson, 2007; Deegan, 2000). It can be argued that the moral duty of financial accounting is to reduce inequity in society and that transparency must be directed towards society as a whole (Nielsen \& Madsen, 2009). In this regard, management thus has a great interest in satisfying the information needs of all interested parties of an organisation.

\section{The Intellectual Capital Capability Approaches}

A 'Capability' is what can be achieved (or what one can do) when these asset categories are combined in a contextual situation. A 'Capability Value' is the economic value of the capability (Ratnatunga et al., 2004). The IC capability approach is to view IC that gives a company's a source of competitive advantage rather than assets or capital in some fixed sense (Ratnatunga, 2002).

There is both a tangible and an intangible aspect to the IC value. The purchase of a franchise outlet may be tangible, but the price paid might not represent only the tangible value. Sometimes, special considerations 
may be present, such as the knowledge workers require to run the franchise outlet. In such cases, the price paid for any particular IC capability is not only its tangible 'value' but rather a value that also incorporates intangible factors. These tangible and intangible value combinations occur when 'the sum is greater than its parts'.

In the corporate world, investors and managers are becoming increasingly aware of the value of intangible assets and how all their assets, both tangible and intangible, combine to produce the capability to enhance their firm's economic value. Ratnatunga et al. (2004) reason that by using specific Expense Leveraged Value Indices (ELVI); it is possible to calculate the capability economic values for all tangible and intangible assets in a firm.

Similarly, expenditure to build Intellectual Capital Capability (ICC) is particularly amenable to such a valuation approach. Such expenses combine and convert tangible and intangible inputs into ICC outputs.

Ratnatunga et al. (2004) and Ratnatunga and Ewing (2005) suggest that there is a strong and demonstrable link between what an organisation spends in a particular period on a capability, and how such expenditure can increase (or if the spend is inadequate, decrease) the capability's value. Such a valuation approach is no different to the traditional revaluation of a non-current asset, which will be dependent on the extent of money expended to increase or maintain its capability.

Ratnatunga et al. (2004) and Ratnatunga and Ewing (2005) calculate capability values via a single-period valuation process using ELVI obtained by statistical means or by consensus. This paper extends their work by demonstrating that the ELVI approach is suitable for taking targeted actions to enhance ICC values. The following equation developed from work originally done by Vidale and Wolfe (1957) demonstrates the relationship of the ELVI to capability values:

Equation 1:

$$
\frac{d S}{d t}=r . E \cdot\left(\frac{M-S}{M}\right)-\delta S
$$


The equation indicates that the change in the economic value $(\mathrm{dS} / \mathrm{dt})$ of a capability-enhancing asset at time ' $t$ ' is a function of five factors:

$\mathrm{E}$ : the costs/expenses incurred to support the capability from purchase date;

$\mathrm{r}$ : the value-increasing constant (ELVI No.1 - defined as the value generated per expense dollar when $\mathrm{S}=0$ );

M: the maximum consensus value of the capability at the current date;

S: the value of the capability at time of purchase; and

$\delta$ : the value-decay constant (ELVI No.2 - defined as the fraction of value lost per time unit when $\mathrm{E}=0$ )

The equation states that the change (increase) in the capability value will be higher when $\mathrm{r}, \mathrm{E}$, and the untapped capability potential are higher, and the value-decay constant is lower. Ratnatunga (2004) used this model to value military capabilities and Ratnatunga and Ewing (2005) to value marketing communications capabilities. In this paper, it will be used to value an Intellectual Capital Capability (ICC) at a point in time.

It stands to reason that the more logistical and financial support is invested in a capability (say on employee education and training) the more capable it becomes; and conversely, if there was no expenditure incurred on it the less capable it becomes. The difficulty lies, however, in estimating the relationship between the expenditure and the resultant capability enhancement or diminution. As a hypothetical example, let us assume that a brand was purchased at a price of $\$ 1,500,00010$ years ago via an acquisition. Since then, assume that the brand owner has expended money (E) to date on the brand for 'enhancement' (e.g. via a strategic brand building promotional campaign) and 'maintenance' (e.g. via brand maintenance advertising) of $\$ 160,000$. Due to the economics of diminishing returns, however, this brand, like all economic assets, would have a maximum sales capability potential, no matter how many financial and other resources are lavished on it. Let us assume that this maximum (management consensus-based) capability potential is $\$ 2,500,000$ at the current date.

Let us now assume that the management, based on its past experience, estimates the value-increasing constant of this brand for each dollar of 
financial support given (r) to be 6 , and the value-decay constant $(\delta)$ had this financial support been withdrawn to be 0.02 .

The ICC valuer can use these variables and constants to calculate the capability value of the brand using the equation 1 presented earlier, as follows:

$$
\begin{aligned}
\left(\frac{\mathrm{dS}}{\mathrm{dT}}\right) & =6 \cdot 160,000 \cdot\left(\frac{2,500,000-1,500,000}{2,500,000}\right)-0.02(1,500,000) \\
\left(\frac{\mathrm{dS}}{\mathrm{dT}}\right) & =6(0.4) .160,000-30,000=\$ 354,000
\end{aligned}
$$

Thus, based on these ELVI, by spending $\$ 160,000$ on capability support, the capability value has been leveraged up by a significant $\$ 354,000$ or a net ELVI of 2.2125 . The total capability value of the brand at that point in time would now be $\$ 1,500,000+354,000=\$ 1,854,000$, which is what it should be worth if it is put up for sale.

Note that if the owner in the preceding example had completely neglected the brand and spent only $\$ 5,000$ on capability support, by applying the capability-enhancing asset equation the change in economic value (dS/dt) works out to be a negative $\$ 18,000$, or a net ELVI of minus 3.6. The brand would now be worth only $\$ 1,482,000$. Thus, all capabilities would have a range of net ELVI, some greater than 1, some between 0 and 1, and some negative. Therefore, the model is not biased only in the positive (capability-enhancing) direction, nor is the resultant value linear to the amount of expenditure. That is, inputs to the model will not always produce a positive result, as a brand not supported at the proper level may result in a weakened market position vis-à-vis other competing brands.

It would be a mistake to aim for global standards in value-enhancing (r) or value-decaying $(\delta)$ constants in IC valuation because the factors that affect the strength of an organisation's IC capability are so diverse. Instead, the aim should be to develop measures tailored to particular IC capabilities, which could be adjusted to take an organisation's unique strengths into account. 


\section{Applying the ICC Approach to Enhance IC Capabilities}

The previous example demonstrates how a value can be calculated at a point in time by considering the ex-post expenditure invested in an IC capability. However, the interdependent nature of ex-ante actions that could be undertaken to enhance ICC values make the application of the above univariate capability valuation model somewhat restrictive. Actions that increase ICC values require an integrated approach. Thus, for the development of the ICC valuation model to provide useful information for ex-ante resource allocation purposes, it needs to be extended in a multivariate manner to deal with complex ICC factor interrelationships.

So (2014) researched the Hong Kong market and recognized seven IC strength factors that affect IC value. So (2014) presented these as the antecedents required to estimate the capability-value consequences of alternative expense-budgeting strategies (see Table 1). For example, IC capability can be viewed as a function of management philosophy, brands and copyrights, education, licensing agreements, know-how, research collaboration and work-related competencies. The impact of these 7 IC factors will differ from industry to industry. In utilities sector, with heavy investment in technological innovation, the investment in know-how was shown to be highly relevant. In others, such as finance sectors, the factors of customer services were shown to be more relevant (So, 2014). So (2014) concluded that managers should develop their specific IC strength factors tailored to their industries, which could be adjusted to in take a company's stage of development into account. 


\section{Management Accounting Frontiers 3 (2020) 25 - 52}

Table 1. IC Strength Factors

IC Strength Factor

Management Philosophy: Actions here mainly focus on the way in which management in a firm perceives the organisation and its employees.

Brands \& Copyrights: Actions here mainly focus on providing reminders to customers to purchase the products and services, while legal action should be enforced to protection of creative and artistic works.

Education: Actions here increase the potential for growth in the longer term by enhancing the education level of employees.

Licensing Agreements: Actions here include obtaining agreements which give the firm the right to sell products, services or technology to other parties.

Know-How: Actions here to support privately maintained expert knowledge on the operation, maintenance, and use of the object product and of its sale, usage or disposition.

Research Collaboration: Actions here to enable researchers in different fields could work together to achieve the common goal of producing new scientific knowledge. Formal or informal research networks are required with the introduction of successive generations of technology.
Reasons for Inclusion

To achieve a high score of IC capability, the mission statement and promoted share value of an organisation are the key factors.

Brands can include service brands that promote quality and reliability, and corporate brands that promote the value of the reputation. Moreover, establishing copyright as a form of intellectual property protects corporate interests.

Better human resources are essential to support people's creativity and to enhance customer services. Investment in human capital is expected to give way to higher productivity of individuals.

The factor emphasizes the relationships that a firm has with its industry network. It captures the knowledge of market channels, customer and supplier relationships. It is the ability of a firm to interact positively with business community members to motivate the potential for wealth creation.

The competitiveness of a firm increases as the human capital becomes increasingly firm-specific. Organisation should base competitiveness on distinctive assets such as know-how and talent which could bring into competitive advantage.

This factor comprises the knowledge embedded in the relationships a firm develops with external entities. It can provide a platform as to how the firm can explore or develop new knowledge so as to sustain its competitive advantage positions. Resources could be pooled at either at a firm or at an industry level, which results in falling cost and growing ease of communication. 
Work-Related Competencies: Actions here to increase a merged set of skills, creative profiles, and personality attributes of employees.
The factor is referred to the combination of specific and non-specific skills possessed by the individuals and the collective workforce of a firm. The competencies of employees could result in effective and/or superior job performance.

In demonstrating the methodology employed in this study, a hypothetical example is used. Taking the results of the content analysis presented in So (2014), seven IC elements (management philosophy, brands \& copyrights, education, licensing agreements, know-how, research collaboration and work-related competencies) that were found to be relevant to IC capability are used for illustrations. The management philosophy, brands, and education are regarded as the largest reported elements, while the licensing agreements, know-how, research collaboration and work-related competencies are the least reported elements in the firms' annual reports (So, 2014).

The seven IC strength factors that affect IC capability are recognised and presented as the pre-conditions (or antecedents) required for the inducement of present and future sales potential of the organisation (which are the consequences) (see Figure 1).The expenses targeted to enhance the IC strength factors act via an intermediate variables of IC capability to generate an effect on sales revenue.

The model will provide a basis for organisation-specific refinement and application. In practice, the IC resource is very diverse and specific to particular organisations. Managers are advised to identify their firms' IC strength factors that could enhance the IC capability. By applying the multivariate analysis in determining the value of IC capability, managers are required to justify the proportion of funds expended on each IC strength factor of their organisations. Thus, the costs incurred in investing in such IC could be compared with the benefits in term of sales potential that is due to an enhanced IC capability value. 
Figure 1. Antecedents and Consequences of ICC

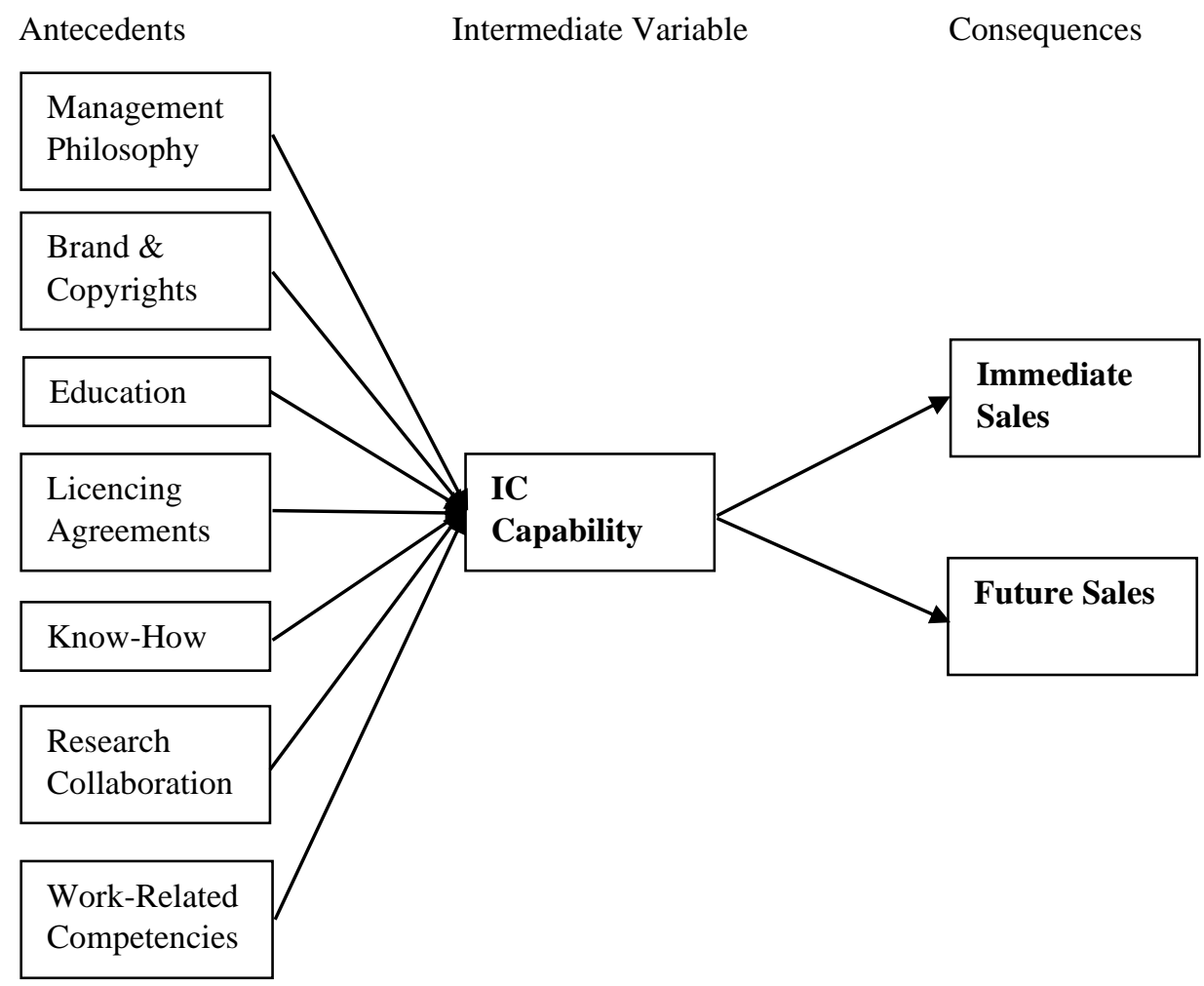

Based both on the preceding literature and conventional wisdom with regards to IC valuation, it can be posited that the expenses targeted to enhance these seven strength factors can potentially have both an attitudinal effect in terms of the recognition and the perceived quality of the ICC, and a behavioural effect on sales. Thus, there needs to be integration of the many IC strengths that constitute the value-enhancing efforts required to enhance ICC value, as the following equation 2 :

$$
\frac{d S}{d t}=\sum_{i}^{N}\left[r_{i} E_{i}\left(\frac{M_{i}-S_{i}}{M_{i}}\right) p_{i}-\delta_{i} S_{i}\right]
$$


The equation indicates that the change in the economic value $(\mathrm{dS} / \mathrm{dt})$ of capability-enhancing activity at time ' $\mathrm{t}$ ' is a function of:

Ei: The costs that should be incurred in supporting the capability of the $i^{\text {th }}$ Intellectual Capital Strength (ICS) variable over a defined period of time.

ri: The value-increasing ELVI constant of the $\mathrm{i}^{\text {th }}$ IC strength variable (defined as the value generated per expense dollar when $\mathrm{S}=0$ ).

M: The maximum consensus value of the Intellectual Capital Capability (ICC) at end of value enhancement period.

S: The current value of the ICC (based on the Equation 1).

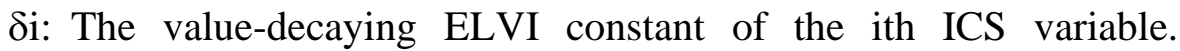
(Defined as the fraction of value lost per time unit when $\mathrm{E}=0$ ).

pi: The proportion of funds expended on the ith ICS variable, where $\sum_{i}^{N} p_{i}=1$

$\mathrm{N}$ : Total number of ICS variables (see Figure 1).

The extension of the univariate model to incorporate ex-ante investment in capability-enhancing intellectual capital strengths requires the derivation of the pi measure for each ICS variable. This will initially have to be a consensus measure, until there is further development in experience in using the model.

In the equation 2 above the value-increasing ELVI constant (ri) is the only factor impacted by the proportion of funds (pi) invested in it. The value-decaying ELVI constant $(\delta \mathrm{i})$ is the diminution of the capability value if there is no further investment of funds in it. Thus, the range of values for ri and $\delta i$ are very different. The value-increasing ri constant is very similar to (say) an advertising sales response function, where each dollar invested in advertising could result in a sales dollar multiple of 4 to 20 times (or more). The only limitation to not spending limitless amounts on advertising (and getting limitless amounts of sales revenue) is first, that the ri constant only holds for a relevant range, and second, that there is a saturation level of sales based on the life cycle of the product. The same relationship is applied to the link between expenses incurred on IC strengths Ei and IC capabilities. The above equation with the Mi variable, defined as the maximum consensus value of a particular IC capability, 
represents the saturation level of capability potential. The range of the value-decreasing $\delta \mathrm{i}$ is, conversely, very limited as a value of 1 in this variable indicates that all value will be lost (i.e. fully amortised within the period) if the support of that particular ICS variable in that period does not have any expenses incurred on it. A value more than 1 indicates that an asset that has no money spent on it will become a liability.

\section{Working Example of the Use of ICC Valuation Model}

The starting point for the ICC valuation is the current market value (S) based on Equation 1, and the maximum consensus value (M) that can be obtained at the end of the value enhancement period of an IC capability. As this paper is discussing capabilities as opposed to tangible asset values, some consensus would need to be obtained as to whether these values also incorporate the intangible aspects of the asset. Let us assume that the current value is $\$ 750,000(\mathrm{~S})$, and the maximum consensus value possible at the end of the value enhancement period $\$ 1,500,000(\mathrm{M})$.

Next, there needs to be estimation by management consensus of the contribution of each of the ICS variables to the enhancement of the IC capability. These are weights (in terms of importance) applied to each of the IC strength (Figure 1) components (or antecedents) required to maintain or increase the ICC value. Table 2 provides hypothetical consensus estimates used to value each ICS variable's current capability (Si) and maximum capability (Mi) at the end of the value enhancement period. 
Management Accounting Frontiers 3 (2020) 25 - 52

Table 2. Contribution of ICS variables to ICC

\begin{tabular}{lcll} 
IC Strength Variable & Weight & Current IC Value & Maximum IC Value \\
\hline Management Philosophy & $35 \%$ & $\$ 262,500$ & $\$ 525,000$ \\
Brands \& Copyrights & $10 \%$ & $\$ 75,000$ & $\$ 150,000$ \\
Education & $8 \%$ & $\$ 60,000$ & $\$ 120,000$ \\
Licensing Agreements & $18 \%$ & $\$ 135,000$ & $\$ 270,000$ \\
Know-How & $5 \%$ & $\$ 37,500$ & $\$ 75,000$ \\
Research Collaboration & $15 \%$ & $\$ 112,500$ & $\$ 225,000$ \\
Work-Related competencies & $9 \%$ & $\$ 67,500$ & $\$ 135,000$ \\
\hline Total & $100 \%$ & $\$ 750,000$ & $\$ 1,500,000$ \\
\hline
\end{tabular}

Let us now assume that $\$ 50,000$ (E) is expected to be spent by the managers on enhancing the ICC during the value enhancement period. This model will request the managers to provide an initial iteration of the expected proportion of funds (pi) they would be expending on each ICS variable, and Table 3 presents these figures.

Table 3. Estimated Percentage Spend on Each IC Strength

\begin{tabular}{lll} 
IC Strength Variable & Iteration 1 & Sensitivity Iteration 2 \\
\hline Management Philosophy & $12 \%$ & $8 \%$ \\
Brands \& Copyrights & $14 \%$ & $18 \%$ \\
Education & $11 \%$ & $22 \%$ \\
Licensing Agreements & $25 \%$ & $28 \%$ \\
Know-How & $13 \%$ & $8 \%$ \\
Research Collaboration & $15 \%$ & $12 \%$ \\
Work-Related competencies & $10 \%$ & $4 \%$ \\
\hline
\end{tabular}


The most difficult part of empirically validating the valuation model will be obtaining data for the various ELVI constants, both valueincreasing (ri) and value-decreasing ( $\delta \mathrm{i})$, for each of the ICS variables in terms of their contribution to ICC value (Table 3). This is mainly due to the different 'value ranges' required for the ri and $\delta i$ constants. Furthermore, as the multivariate model equation was being used (Equation 2), the non-linear functions will be difficult to work with in obtaining consensus values. However, repeated trials of different ELVI values using an Excel model should provide the managers with a reasonable understanding of the dynamics of the equation. Table 4 gives hypothetical consensus values (Note that the values in the last column of Table 4 are derived using the multivariate Equation 2 for each of the ICS variables).

As the total spend on value-enhancing activities is budgeted at $\$ 50,000$, the ICS capability incremental value component of the ICC value based on the proportion of funds expended on each ICS variable is approximately a positive $\$ 113,100$. This means that the $\$ 50,000$ to be spent is more than adequate to not only maintain, but also enhance the IC capability value from $\$ 750,000$ to $\$ 863,100$ over the value enhancement period (See Table 5). 
Management Accounting Frontiers 3 (2020) 25 - 52

Table 4. IC Capability Growth

\begin{tabular}{lllll} 
IC Strength Variable & $\begin{array}{l}\text { Value- } \\
\text { Increasing } \\
\text { ELVI } \\
\text { Constant }\end{array}$ & $\begin{array}{l}\text { Value- } \\
\text { Decaying } \\
\text { ELVI } \\
\text { Constant }\end{array}$ & $\begin{array}{l}\text { \%of Costs } \\
\text { Expended }\end{array}$ & $\begin{array}{l}\text { Contribution } \\
\text { to } \\
\text { Incremental } \\
\text { ICC }\end{array}$ \\
\hline Management Philosophy & 6.5 & 0.01 & $12 \%$ & $\$ 16,875$ \\
Brands \& Copyrights & 8.5 & 0.3 & $14 \%$ & $\$ 7,250$ \\
Education & 9 & 0.4 & $11 \%$ & $\$ 750$ \\
Licensing Agreements & 10 & 0.04 & $25 \%$ & $\$ 57,100$ \\
Know-How & 3.5 & 0.05 & $13 \%$ & $\$ 9,500$ \\
Research Collaboration & 8 & 0.2 & $15 \%$ & $\$ 7,500$ \\
Work-Related competencies & 7 & 0.05 & $10 \%$ & $\$ 14,125$ \\
\hline Incremental IC Capacity Value & & & & $\$ 113,100$ \\
\hline
\end{tabular}

Table 5. Contributions of Capabilities Value

\begin{tabular}{llll} 
IC Strength Variable & $\begin{array}{l}\text { Current IC } \\
\text { Value }\end{array}$ & $\begin{array}{l}\text { Incremental IC } \\
\text { Strength }\end{array}$ & $\begin{array}{l}\text { Projected IC } \\
\text { Capability } \\
\text { Value }\end{array}$ \\
\hline Management Philosophy & $\$ 262,500$ & $\$ 16,875$ & $\$ 279,375$ \\
Brands \& Copyrights & $\$ 75,000$ & $\$ 7,250$ & $\$ 82,250$ \\
Education & $\$ 60,000$ & $\$ 750$ & $\$ 60,750$ \\
Licensing Agreements & $\$ 135,000$ & $\$ 57,100$ & $\$ 192,100$ \\
Know-How & $\$ 37,500$ & $\$ 9,500$ & $\$ 47,000$ \\
Research Collaboration & $\$ 112,500$ & $\$ 7,500$ & $\$ 120,000$ \\
Work-Related competencies & $\$ 67,500$ & $\$ 14,125$ & $\$ 81,625$ \\
\hline Total & $\$ 750,000$ & $\$ 113,100$ & $\$ 863,100$ \\
\hline
\end{tabular}




\section{Using the Model for Alternative Intellectual Capital Investments Sensitivity Analysis}

Let us assume that, due to budgetary constraints, the managers wish to only maintain the same IC capability (and hence the same sales potential as current), rather than the increased incremental capability currently achieved due to a high spend level of $\$ 50,000$. Then (using the goal-seek function in Excel) the model equation will indicate that $\$ 21,056$ will need to be expended to maintain its IC capability at its initial value. This would be the zero-based level of expenditure on IC strength-enhancing activities for IC Capability maintenance (i.e. nil ICC increase). Cutting costs below this would result in a loss of capability (see Table 6). This concept is no different to the expenses a company would need to spend on repairs and preventive maintenance of its tangible assets (e.g. motor vehicles). Just to keep the vehicles running at its current level of economic capability, a certain level of expenses would need to be incurred.

Table 6. IC Capability Maintenance

\begin{tabular}{lllll} 
IC Strength Variable & $\begin{array}{l}\text { Value- } \\
\text { Increasing } \\
\text { ELVI } \\
\text { Constant }\end{array}$ & $\begin{array}{l}\text { Value- } \\
\text { Decaying } \\
\text { ELVI }\end{array}$ & $\begin{array}{l}\text { \%o of Costs } \\
\text { Constant }\end{array}$ & $\begin{array}{l}\text { Contribution } \\
\text { to } \\
\text { Incremental } \\
\text { ICC }\end{array}$ \\
\hline Management Philosophy & 6.5 & 0.01 & $12 \%$ & $\$ 5,586$ \\
Brands \& Copyrights & 8.5 & 0.3 & $14 \%$ & $\$(9,972)$ \\
Education & 9 & 0.4 & $11 \%$ & $\$(13,577)$ \\
Licensing Agreements & 10 & 0.04 & $25 \%$ & $\$ 20,920$ \\
Know-How & 3.5 & 0.05 & $13 \%$ & $\$ 2,915$ \\
Research Collaboration & 8 & 0.2 & $15 \%$ & $\$(9,866)$ \\
Work-Related competencies & 7 & 0.05 & $10 \%$ & $\$ 3,994$ \\
\hline Incremental IC Capacity Value & & & & $\$ 0$ \\
\hline
\end{tabular}


Note that, due to the non-linear function in the equation used, a reduction in budget spend of only $\$ 28,944$ (i.e. reduce from $\$ 50,000$ to $\$ 21,056)$ results in the incremental IC capability value decreasing significantly, from $\$ 113,100$ to zero. As one can see, therefore, such a model will be extremely useful in helping resolve recurring issues pertaining to targeted spending on ICSs. One can see from Table 6 that even this zero-based expenditure level, while maintaining the capability value overall, is inadequate to maintain some individual ICS component values (e.g. brands and copyrights, education, and research collaboration now all show negative capability values; while in Table 4 they are positive). Thus, the goal seek function can be utilised again to ascertain the minimum expenditure required to maintain (say) the level of education.

The model can also increase ICC values by expending different proportions of funds on the individual ICS variables. Using the iteration 2 column from Table 3, and keeping the total spend at the iteration 1 level of (the original) $\$ 50,000$, the incremental ICC value increases to $\$ 126,475$ (see Table 7). When comparing this to Table 4 (where ICC value increased by $\$ 113,100$ ), an additional IC capability value increase of $\$ 13,375$ can be estimated. Thus, the company has increased its ICC value by spending the same amount of money, but simply changing its strategic focus on the ICS variables that produce the most IC capability enhancement. 
Table 7. IC Capability Growth (Iteration 2)

\begin{tabular}{lllll} 
IC Strength Variable & $\begin{array}{l}\text { Value- } \\
\text { Increasing } \\
\text { ELVI } \\
\text { Constant }\end{array}$ & $\begin{array}{l}\text { Value- } \\
\text { Decaying } \\
\text { ELVIM } \\
\text { Constant }\end{array}$ & $\begin{array}{l}\text { \% of Costs } \\
\text { Expended }\end{array}$ & $\begin{array}{l}\text { Contribution } \\
\text { to } \\
\text { Incremental } \\
\text { ICC }\end{array}$ \\
\hline Management Philosophy & 6.5 & 0.01 & $8 \%$ & $\$ 10,375$ \\
Brands \& Copyrights & 8.5 & 0.3 & $18 \%$ & $\$ 15,750$ \\
Education & 9 & 0.4 & $22 \%$ & $\$ 25,500$ \\
Licensing Agreements & 10 & 0.04 & $28 \%$ & $\$ 64,600$ \\
Know-How & 3.5 & 0.05 & $8 \%$ & $\$ 5,125$ \\
Research Collaboration & 8 & 0.2 & $12 \%$ & $\$ 1,500$ \\
\hline Work-Related competencies & 7 & 0.05 & $4 \%$ & $\$ 3,625$ \\
\hline Incremental IC Capacity Value & & & $\$ 126,475$ \\
\hline
\end{tabular}

\section{Reporting ICC Values in Financial Statements}

Three approaches have suggested by Leadbeater (2000) to integrate the above measures in organisational reports to stakeholders. These approaches are as follows:

- The Fully Integrated Approach: The approach here takes the view that the traditional financial accounts will remain the focal point of organisational reporting for some time, and therefore it is appropriate that the new measures detailed above are incorporated in these statements to help investors value intangibles. This approach would involve accounting procedures used routinely in organisational acquisitions to value intangibles, as well as key performance indexbased ELVIs used in leveraging internally acquired intangible asset values to the books as capability values. This approach would require 'market consensus valuations' based on non-financial measures that are relevant, relatively easy to collect and have a proven relationship to capability value.

- The Supplementary Approach: Here separate ICC financial statements are prepared, to sit alongside the traditional statements 
prepared as per accounting standards and financial reporting standards. These will incorporate traditional financial information as a measure of success and as a resource for investment, but the focus will mainly be on measuring the capability-enhancing intangible assets, and the corresponding intellectual capital.

- The Hybrid Approach: This is a compromise approach where the incorporation of intangible capability asset values is a gradual process. The hybrid approach is designed to allow organisations to gradually combine traditional and novel ways of valuing asset capabilities. It would permit them to deal more effectively with volatility and uncertainty by providing 'half-way houses' and 'revisable rolling accounts'. Industry standards for disclosing relevant non-financial information about intangibles would allow more robust links to be made between investment in intangibles and market valuations, if appropriate. Traditional financial accounts would become more relevant and responsive by becoming flexible and adjustable to suit specific circumstances.

The concept of half-way houses refers to when an organisation 'quarantines' its intangible capability values before allowing them to migrate to the balance sheet. Intangibles are valued as capability assets without putting them on the actual balance sheet until their value is more established. This would allow the organisation to adopt a more flexible approach by stating possible ranges for intangible asset values.

A similar concept is that of the revisable rolling accounts. For example, it might not be wise to capitalise the R\&D of a high-risk new technology-based capabilities at an early stage of development because the future benefits would be so uncertain. However, at some point, when the technology and the market have become less volatile, capitalisation may become more realistic. It might then be worth restating past accounts to show how they would have looked if the R\&D had been capitalised. The justification for this approach is that the accounts are the financial history of a company and, like most histories; they should be revised in the light of new information.

Whatever approach to implementation is adopted it will be necessary to initially estimate the current capability value of all tangible and intangible assets of the organisation, and have an ICC Balance Sheet as at a particular date' after which the double-entry accounting approach outlined previously could be carried out. An example of an ICC Balance Sheet provided in Ratnatunga et al.(2004) is presented at Figure 2. 
Management Accounting Frontiers 3 (2020) 25 - 52

Figure 2. ICC Balance Sheet for Commercial Organisation

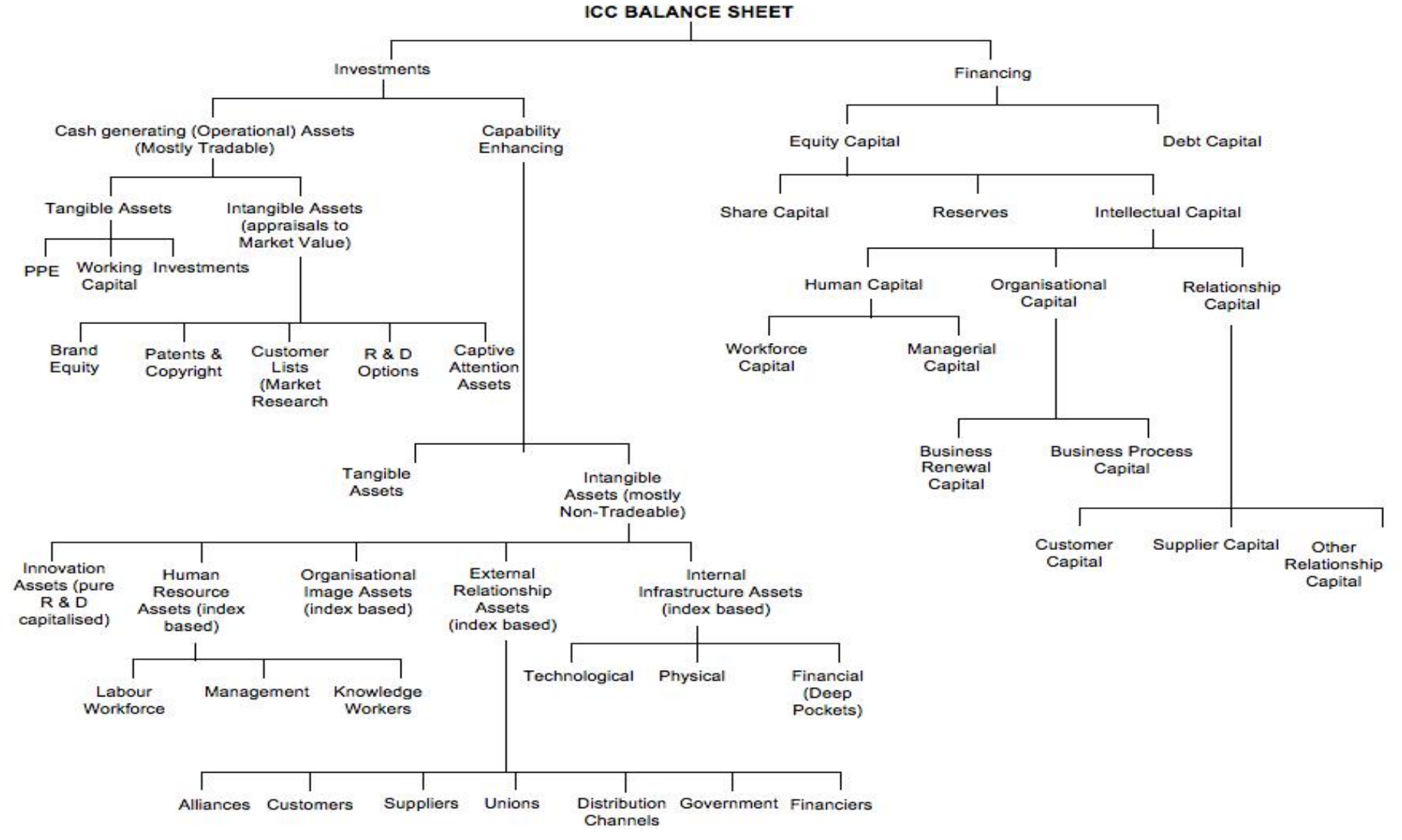

Adapted from Ratnatunga et al. (2004) 


\section{Discussion and Conclusion}

This paper provides a normative model of IC valuation and reporting by examining to what extent the Capability Economic Value of Intangible and Tangible Assets (CEVITA ${ }^{\mathrm{TM}}$ ) approach (Ratnatunga et al., 2004) can be adapted and applied to the valuation of intellectual capital capability (ICC) at a point in time, and it also demonstrates how this approach can be used in ICC enhancing processes. In addition, it has pointed out the firm's Intellectual Capital Strengths (ICS) that can be targeted and provides an ex-ante approach to building intellectual capital value. Accordingly, managers are provided with a framework to calculate the value of their intellectual capital and invest successfully in the appropriate elements of their IC strengths.

The process of drawing up an ICC Balance Sheet focuses managers on the capabilities enhanced by such intellectual capital. By applying an ICC balance sheet that integrates the intangible and tangible components, managers have a more realistic tool to present clearer, and statistically supported arguments to their board when recommending intellectual capital expenditures that enhance values. . It also helps managers and investors to visualise the role tangible and intangible assets play in combination in creating organisational value.

From a traditional perspective, it is easily understood that the value of the company's investments belongs to shareholders and debt holders in proportions reflecting their respective contributions and the contractual arrangements. Most corporate balance sheets have either focused their attention on the company value from the shareholder point of view; or from a total financing (equity and debt) point of view.

According to stakeholder theory, the presence of intangible assets modifies the allocation of residual claims as company performance can substantially affect the wealth of those stakeholders embodying some of the critical factors for company success. Obviously, the economic value created by the business system is no longer being regarded as belonging exclusively to its financiers (i.e. shareholders and debtholders) but should be shared by various stakeholders.

With reference to the stakeholder theory, a best-practice model of IC reporting should serve the needs of different stakeholders of a firm. The ICC balance sheet brings the value of a business system as a whole within the framework of the company balance sheet. It is a way of expressing the composition of the market value of assets and liabilities. 
More precisely, the asset side displays the market value of all the resources contributing to the company development, including those intangible assets which are not directly controlled by the company, such as capabilities and trust it shares with managers, employees, customers, and suppliers.

The ICC measure presented in this paper is a pragmatic approach to enhancing IC capability within an organization by utilizing ELVI to calculate the value of intangible assets. Most traditional IC measurement models are either market-based measures or index-based measures. The multivariate model of this paper that incorporates specific IC strength not only provides a methodology for managers to calculate the ICC under the organization-specific refinement, but also can be applied for budgeting and valuation purposes.

In this paper, the constructed framework can be contextually tested; and used as a theoretical foundation for future empirical studies in relation to IC valuation and reporting. The normative framework will explore the possibility of research studies by using the CEVITATM measure. In particular, case study could be carried out by identifying the IC strength factors and valuing the capability assets in an organisational context. It is hoped that the current model provides a starting point for guiding research or practice related to the valuation and reporting of IC. 


\section{References}

Abeysekera, I. and Guthrie, J., (2004), "Human Capital Reporting in a Developing Nation". British Accounting Review, Vol. 36 No. 3, pp. 251268.

Abeysekera, I. and Guthrie, J., (2005), “An Empirical Investigation of Annual Reporting Trends of Intellectual Capital in Sri Lanka", Critical Perspectives on Accounting, Vol. 16 No. 3, pp. 151-163.

Beattie, V. and Thomson, S. J., (2007), "Lifting the Lid on the Use of Content Analysis to Investigate Intellectual Capital Disclosure", Accounting Forum, Vol. 31 No. 2, pp. 129-163.

Bozzolan, S., Favotto, F. and Ricceri, F., (2003), "Italian Annual Intellectual Capital Disclosure: An Empirical Disclosure", Journal of Intellectual Capital, Vol. 4 No.4, pp. 543-558.

Brennan, N., (2001), "Reporting Intellectual Capital in Annual Reports: Evidence from Ireland", Accounting, Auditing and Accountability Journal, Vol. 14 No. 4, pp. 423-436.

Bukh, P. N., (2003), "The Relevance of Intellectual Capital Disclosure: A Paradox?", Accounting, Auditing and Accountability Journal, Vol. 16 No.1, pp. 49-56.

Campbell, D. and Abdul Rahman M. R. A., (2010), "A Longitudinal Explanation of Intellectual Capital Reporting in Marks \& Spencer Annual Reports 1978-2008”, British Accounting Review, Vol. 42 No. 1, pp. 5670.

Chen, M. C., Cheng, S. J. and Hwang, Y., (2005), "An Empirical Investigation of the Relationship between Intellectual Capital and Firm's Market Value and Financial Performance", Journal of Intellectual Capital, Vol. 6 No. 2, pp. 159-176.

Choong, K. K., (2008), "Intellectual Capital: Definitions, Categorization and Reporting Models", Journal of Intellectual Capital, Vol. 9 No. 4, pp. 609-638.

Cuganesan, S. and Petty, R., (2010), "Intellectual Capital Measurement and Reporting: Issues and Challenges for Multinational Organizations", in K O'Sullivan (ed.), Strategic Intellectual Capital Management in Multinational Organizations: Sustainability and Successful Implications, New York Institute of Technology, New York, pp. 75-94.

Deegan, C., (2000), Financial Accounting Theory, McGraw-Hill, Sydney. 
Deegan, C. and Gordon, B., (1996), "A Study of the Environmental Disclosure Policies of Australian Corporations", Accounting and Business Research, Vol. 26 No. 3, pp. 187-199.

Eccles, R. G. and Serafeim, G., (2011), "Accelerating the Adoption of Integrated Reporting", in F. de Leo and M. Vollbracht (ed.), CSR Index, Innovation Publishing, Wheeling, pp. 70-92.

Freeman, R. E., (1984), Strategic Management: A Stakeholder Approach, Pitman, Boston.

Freeman, R. E., Wicks, A. C. and Parmar, B., (2004), "Stakeholder Theory and the Corporate Objective Revisited", Organisation Science, Vol. 15 No. 3, pp. 364-369.

Guthrie, J., Petty R., Yongvanich, K. and Ricceri, F., (2004), "Using Content Analysis as a Research Method to Inquire into Intellectual Capital Reporting", Journal of Intellectual Capital, Vol. 5 No. 2, pp. 282-293.

Hsu, Y. H. and Fang, W., (2009), "Intellectual Capital and New Product Development Performance: The Mediating Role of Organizational Learning Capability", Technological Forecasting and Social Change, Vol. 76 No. 5, pp. 664-677.

Kong, E., (2010), “Analyzing BSC and IC's Usefulness in Non-Profit Organizations", Journal of Intellectual Capital, Vol. 11 No. 3, pp. 284304.

Leadbeater, C., (2000), New Measures for the New Economy, The Institute of Chartered Accountants in England and Wales, London.

Martin-de-Castro, G., Delgado-Verde, M., Lopez-Saez, P. and NavasLopez, J. E., (2011), "Towards 'An Intellectual Capital-Based View of the Firm: Origins and Nature", Journal of Business Ethics, Vol. 98 No. 4, pp. 649-662.

McVea, J. H. and Freeman, R. E., (2005), "A Names-and-Faces Approach to Stakeholder Management", Journal of Management Inquiry, Vol. 14 No. 1, pp. 57-69.

Menor, L. J., Kristal, M. M. and Rosenzweig, E. D., (2007), “Examining the Influence of Operational Intellectual Capital on Capabilities and Performance", Operations Management, Vol. 9 No. 4, pp. 559-578.

MERITUM, (2002), Guidelines for Managing and Reporting on Intangibles (Intellectual Capital Report), European Union, Brussels. 
Mouritsen, J., (2006), "Problematising Intellectual Capital Research: Ostensive Versus Performative IC", Accounting, Auditing and Accountability Journal, Vol. 19 No. 6, pp. 820-841.

Nielsen, C. and Madsen, M. T., (2009), "Discourses of Transparency in the Intellectual Capital Debate: Moving from Generic Reporting Models to Management Defined Information", Critical Perspectives on Accounting, Vol. 20 No. 7, pp. 847-854.

Ratnatunga, J., (2002), "The Valuation of Capabilities: A New Direction from Management Accounting Research", Journal of Applied Management Accounting Research, Vol. 1 No. 1, pp. 1-15.

Ratnatunga, J. and Ewing, M., (2005), "The Brand Capability Value of Integrated Marketing Communication (IMC)", Journal of Advertising, Vol. 34 No. 4, pp. 25-40.

Ratnatunga, J., Gray, N. and Balachandran, K. R., (2004), "CEVITA: The Valuation and Reporting of Strategic Capabilities", Management Accounting Research, Vol. 15 No. 1, pp. 77-105.

Riahi-Belkaoui, A., (2003), "Intellectual Capital and Firm performance of US Multinational Firms: A Study of the Resource-Based and Stakeholder Views", Journal of Intellectual Capital, Vol. 4 No. 2, pp. 215-226.

Seetharaman, A., Sooria, H. H. and Saravanan, A. S., (2002), "Intellectual Capital Accounting and Reporting in Knowledge Economy", Journal of Intellectual Capital, Vol.3 No. 2, pp. 128-148.

So, M., (2014), The Voluntary Disclosure of Intellectual Capital by Hong Kong Companies: A Descriptive and Normative Study, PhD Dissertation, University of South Australia.

So, M., (2018), "Management Knowledge Assets: A Review of the Models Used to Measure and Report Intellectual Capital", Management Accounting Frontiers, Vol. 1, pp. 15-44.

Sveiby, K. E., (1997), "The Intangible Assets Monitor", Journal of Human Resource Costing and Accounting, Vol. 2 No. 1, pp. 73-97.

Tan, P., Plowman, D. and Hancock, P., (2007), "Intellectual Capital and Financial Returns of Companies", Journal of Intellectual Capital, Vol. 8 No. 1, pp. 76-95. 
Van Marrewijk, M., (2003), "Concepts and Definitions of CSR and Corporate Sustainability: Between Agency and Communion", Journal of Business Ethics, Vol. 44 no. 2, pp. 95-105.

Vidale, M. L. and Wolfe, H. B., (1957), “An Operations-Research Study of Sales Response to Advertising", Operations. Research, Vol. 5 No. 3, pp. 370-381.

Youndt, M. A., Subramaniam, M. and Snell, S. A., (2004), "Intellectual Capital Profiles: An Examination of Investments and Returns", Journal of Management Studies, Vol. 41 No. 2, pp. 335-361. 